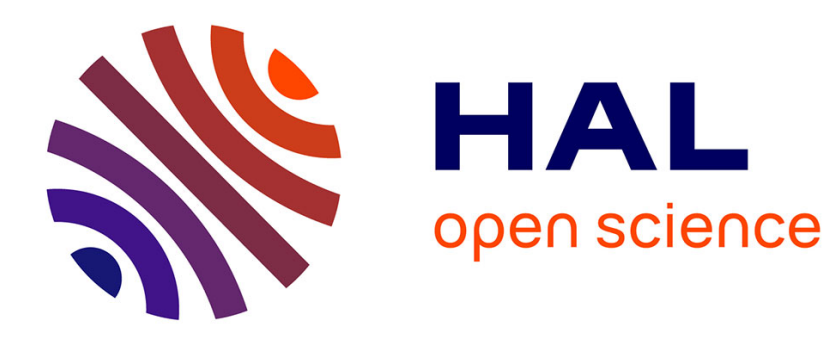

\title{
Métabolisme protéique chez le poulet en croissance. Effet des protéines alimentaires
}

Sophie Tesseraud

\section{To cite this version:}

Sophie Tesseraud. Métabolisme protéique chez le poulet en croissance. Effet des protéines alimentaires.

Productions Animales, 1995, 8 (3), pp.197-212. hal-02702313

\section{HAL Id: hal-02702313 \\ https://hal.inrae.fr/hal-02702313}

Submitted on 1 Jun 2020

HAL is a multi-disciplinary open access archive for the deposit and dissemination of scientific research documents, whether they are published or not. The documents may come from teaching and research institutions in France or abroad, or from public or private research centers.
L'archive ouverte pluridisciplinaire HAL, est destinée au dépôt et à la diffusion de documents scientifiques de niveau recherche, publiés ou non, émanant des établissements d'enseignement et de recherche français ou étrangers, des laboratoires publics ou privés. 
INRA Prod. Anim., 1995, 8 (3), 197-212

\section{S. TESSERAUD}

INRA Station de Recherches Avicoles 37380 Nouzilly

\section{Métabolisme protéique chez le poulet en croissance. Effet des protéines alimentaires}

Améliorer le potentiel de croissance des animaux et transformer plus efficacement l'aliment en protéines animales ont constitué depuis longtemps des objectifs prioritaires en aviculture. Dès lors que l'on cherche à diminuer les pertes d'azote, sources potentielles de pollution, à améliorer le développement des masses musculaires et à réduire l'engraissement, il apparaît nécessaire de limiter la consommation globale de protéines et de mieux formuler les aliments, en particulier en recourant aux acides aminés de synthèse. La quantification de la synthèse et de la dégradation des protéines permet d'expliquer les variations de masse protéique et de comprendre le déterminisme de la fixation des protéines chez l'animal en croissance. Pourtant, de façon surprenante, le métabolisme protéique des oiseaux n'a encore été que peu étudié in vivo. Nous ferons donc le point des connaissances sur la régulation du métabolisme protéique par les protéines alimentaires chez le poulet en croissance.

\section{Résumé}

Pour assurer une croissance musculaire maximale tout en évitant de gaspiller l'azote, une possibilité consiste à diminuer l'apport alimentaire de protéines et rééquilibrer les régimes en les supplémentant en acides aminés industriels. Connaître les conséquences des variations de l'apport protéique alimentaire (quantités et composition en acides aminés) sur les activités respectives de la synthèse et de la dégradation des protéines, dont le bilan détermine le dépôt protéique, permet de rationaliser cette démarche.

Les méthodes de mesure de la synthèse des protéines les plus couramment employées sont présentées en insistant particulièrement sur les hypothèses sur lesquelles elles reposent et leurs limites. Les techniques permettant d'estimer la dégradation des protéines sont également brièvement discutées. Le renouvellement des protéines tissulaires et corporelles varie en fonction de facteurs liés à l'animal : le taux de synthèse diminue avec l'âge, notamment dans les muscles squelettiques, et le taux de dégradation est très lié au type génétique du poulet.

Le taux protéique de la ration modifie le métabolisme protéique par des effets propres dus aux quantités de protéines ingérées ainsi que par des effets liés aux variations de ces niveaux d'apports (restriction puis réalimentation protéique). La composition en acides aminés des protéines alimentaires joue également un rôle important. Ainsi la diminution de l'apport en protéines ou en un acide aminé produit une réduction des quantités de protéines synthétisées et, dans une moindre mesure, de celles dégradées. Les mécanismes régulant le dépôt protéique lorsque les apports quantitatifs et qualitatifs d'acides aminés varient, restent cependant mal connus. L'approfondissement de leur étude au niveau de différents tissus et organes, en intégrant les facteurs physiologiques et hormonaux, permettrait de mieux raisonner la supplémentation en acides aminés. 
rapport à celles présentes dans les protéines (taux ou vitesses fractionnaires, en \%/j). Précisons que les intensités, qui sont des degrés d'activité, peuvent être exprimées par chacun des paramètres ci-dessus.

Nous exposerons les principales techniques de mesure de la synthèse des protéines, notamment celles faisant appel aux traceurs radioactifs, avec une mention particulière pour la technique de large dose ou "flooding dose ". Notons que les isotopes stables $\left({ }^{13} \mathrm{C}\right.$, ${ }^{15} \mathrm{~N}$ ) peuvent aussi être utilisés, mais, en pratique, ils sont employés principalement chez l'homme ou chez les espèces de taille importante. Nous présenterons ensuite les techniques permettant d'estimer la dégradation des protéines.

\section{a / Mesure de la synthèse protéique}

La mesure de l'intensité de la protéosynthèse peut être effectuée soit directement soit indirectement. La mesure directe repose sur la détermination de la vitesse d'incorporation dans les protéines tissulaires d'un acide aminé marqué (traceur) introduit dans le compartiment (ou pool) précurseur. Elle nécessite la détermination de la radioactivité spécifique (RAS) du traceur dans les protéines et dans ce pool. Or le véritable pool précurseur correspond aux acides aminés liés aux ARN de transfert (aminoacyl-tRNA) (figure 2). Il faudrait donc mesurer la RAS de ces derniers, mais ceci est difficile à réaliser techniquement, essentiellement en raison de la très courte demi-vie des aminoacyl-tRNA et de leur labilité. De nombreux auteurs utilisent donc soit la RAS du marqueur dans le pool extracellulaire, soit la RAS du marqueur intracellulaire, la RAS des acides aminés extracellulaires étant assimilée à celle du marqueur dans le plasma et celle des acides aminés intracellulaires étant supposée égale à la RAS du marqueur dans les homogénats tissulaires. Ces approximations encadrent la valeur de la RAS des aminoacyl-tRNA et conduisent à des estimations qui délimitent une plage de mesure dont l'amplitude dépend du mode d'administration du traceur (Obled 1988).

Parmi ces méthodes de mesure directe, la technique de surcharge ou large dose en un acide aminé marqué est la plus appropriée pour mesurer avec exactitude la vitesse fractionnaire de synthèse $\mathrm{Ks}_{\mathrm{s}}$ des protéines tissulaires (McNurlan et al 1979, Garlick et al 1980, Attaix et al 1986). L'injection d'une grande quantité d'acide aminé non radioactif combinée à une dose traceuse du même acide aminé radioactif inonde les pools d'acides aminés libres. Il en résulte une RAS constante, sensiblement équivalente dans le plasma et les tissus - la RAS tissulaire dans le foie ou le muscle représente au moins $90 \%$ de la valeur plasmatique (Garlick et al 1980) - et au même niveau que la RAS du véritable précurseur de la synthèse protéique soit l'aminoacyl-tRNA. Cette méthode présente également l'avantage de permettre des mesures sur une période courte de l'ordre de 10 à 20 minutes. Il est cependant nécessaire de prélever des protéines tissulaires, ce qui impose soit l'abattage des animaux, soit des biopsies. Une autre limite de cette méthode serait liée à l'influence éventuelle de la surcharge sur l'intensité de la protéosynthèse. La possibilité d'un artéfact expérimental est une question non encore complètement résolue mais qui a été discutée en détail dans une revue récente de Garlick et al (1994). Signa-

Figure 2. Origines cellulaires des acides aminés destinés à la synthèse protéique (d'après Garlick et al 1994).




lons que le choix de l'acide aminé traceur est primordial pour la mesure de la protéosynthèse (Obled et al 1989) : il doit tout d'abord être abondant dans les protéines majeures du tissu étudié ; mais il est aussi important d'utiliser un acide aminé essentiel très soluble qui puisse donc être injecté dans de petits volumes. De plus, le pool de cet acide aminé doit être facilement saturable. Enfin, bien sûr, comme signalé ci-dessus, la surcharge en ce traceur ne doit pas influencer les mesures du taux de synthèse des protéines.

La synthèse protéique peut être estimée indirectement grâce à la perfusion continue, souvent par voie intraveineuse, du marqueur sans mesure de son incorporation dans les protéines. Elle est déduite du flux F (ou perte plasmatique du composé marqué) et du catabolisme $\mathrm{C}$, selon la formule : $\mathrm{S}=\mathrm{F}-\mathrm{C}$, (cf figure 1). Cette méthode présente comme principales limites : (1) les valeurs de synthèse sont calculées par différence avec une faible précision, voire une inexactitude ; (2) la RAS n'est en général pas déterminée dans le véritable compartiment précurseur de la synthèse protéique constitué par les aminoacyltRNA, ce qui conduit à une approximation de la synthèse protéique; (3) la mesure peut être erronée à cause du recyclage du traceur pendant la perfusion ; toutefois, d'après Schwenk et al (1985), le recyclage ne devient significatif que lorsque la durée de la perfusion dépasse 12 heures; (4) la mesure réalisée au niveau du corps entier ne renseigne pas sur l'activité du métabolisme protéique dans les tissus ou organes particuliers. Or cette activité peut réagir de façon différente selon les tissus aux facteurs qui la régulent. Cette méthode est cependant fréquemment employée, surtout chez les gros animaux et l'homme.

Une approche des mécanismes métaboliques sous-jacents et de la régulation du métabolisme protéique peut être faite en s'intéressant à la machinerie de la synthèse protéique elle-même. L'intensité de la synthèse résulte de l'abondance des ribosomes et de leur efficacité. Le calcul du rapport ARN total/protéines, appelé capacité ribosomale (au moins $80 \%$ de l'ARN provient des ribosomes), permet de caractériser le potentiel de synthèse. L'efficacité ribosomale ou activité de l'ARN qui traduit l'efficacité de la traduction est appréciée en rapportant la vitesse de synthèse à l'unité d'ARN.

\section{b / Mesure de la dégradation protéique}

Si on sait estimer l'intensité de la synthèse des protéines, il n'existe pas de méthodes réellement fiables de mesure de la dégradation in vivo. La protéolyse peut être estimée directement après injection d'un bolus d'acide aminé radioactif et mesure de la baisse du marqueur dans les protéines en fonction du temps. Cette technique, basée sur l'examen de la décroissance des protéines marquées, est peu utilisée (problème de recyclage du traceur et de durée des mesures). Une autre méthode directe, beaucoup plus courante, consiste à mesurer la $\mathrm{N}^{\top}$-méthylhistidine $\left(\mathrm{N}^{\tau}\right.$ $\mathrm{MH}$, aussi appelée 3-méthylhistidine) excrétée, produit du catabolisme des protéines musculaires. Le principe de cette mesure est que la $\mathrm{N}^{\top}-\mathrm{MH}$ n'est ni réutilisée, ni métabolisée, et excrétée uniquement au niveau urinaire avec une réabsorption tubulaire minime (Young et Munro 1978, Long et al 1975). Son utilisation pour quantifier la protéolyse musculaire est parfois controversée (Rennie et Millward 1983) ou même impossible chez certaines espèces (porc, mouton) qui n'éliminent pas quantitativement la $\mathrm{N}^{\mathrm{r}}$ $\mathrm{MH}$ mais l'incorporent dans un dipeptide (balenine). Cependant, des études réalisées chez le poulet ont montré que l'excrétion de $\mathrm{N}^{ }$-MH constituait un bon index de la dégradation des protéines contractiles (Saunderson et Leslie 1983, Tomas et al 1988).

Par ailleurs, deux techniques indirectes permettent d'estimer la protéolyse :

1 - Avec la méthode de perfusion continue du traceur, on peut faire une estimation de la dégradation des protéines $D$ (cf figure 1) grâce à la formule : $\mathrm{D}=\mathrm{F}-\mathrm{I}$, où $\mathrm{F}$ est le flux apparent et I correspond aux apports alimentaires.

2 - Chez l'animal en croissance, la vitesse fractionnaire de dégradation des protéines $(\mathrm{Kd}, \% / \mathrm{j})$ est en général appréciée par différence entre les vitesses fractionnaires de synthèse $(\mathrm{Ks})$ et de croissance $(\mathrm{Kg})$ des protéines exprimées dans les mêmes unités, $\mathrm{Kd}=\mathrm{Ks}$ $\mathrm{Kg}$. Les taux de croissance $(\mathrm{Kg})$ des protéines tissulaires sont mesurées en abattant des lots d'animaux sur une période de quelques jours encadrant le jour de mesure des Ks. Les principaux risques d'erreur proviennent des échelles de temps de mesure très différentes : les quelques minutes pendant lesquelles le taux de protéosynthèse est mesurée, ne sont pas nécessairement représentatives des quelques jours nécessaires pour évaluer le taux d'accroissement de la masse des protéines. Signalons que Muramatsu et al (1990) ont tenté de développer chez le poulet une méthode de mesure de la protéolyse corporelle sur une période d'une heure.

Connaître les avantages et les limites des méthodes de quantification du métabolisme protéique permet de comprendre la variabilité des résultats trouvés selon les auteurs en fonction de la technique utilisée.

\section{2 / Variations liées à l'animal}

\section{a / Influence de l'âge}

Chez le poulet, peu d'auteurs ont mesuré l'influence de l'âge sur le métabolisme protéique tissulaire in vivo. Nous avons rassemblé les résultats de la littérature concernant l'évolution de la protéosynthèse avec l'âge (tableau 1) en précisant la méthode de mesure utilisée. Muramatsu et Okumura (1985) enregistrent une chute progressive du 
Tableau 1. Evolution en fonction de l'âge du taux de synthèse des protéines $K s$ (\%/j) chez le poulet.

\begin{tabular}{|c|c|c|c|c|c|c|c|c|c|c|}
\hline \multirow{2}{*}{ Référence } & \multirow{2}{*}{$\begin{array}{l}\text { Méthodes } \\
\text { de mesure }\end{array}$} & \multirow{2}{*}{ Tissus (1) } & \multicolumn{7}{|c|}{ Age (semaines) } & \multirow{2}{*}{ Signif. } \\
\hline & & & 1 & 2 & 3 & 4 & 5 & 6 & 7 & \\
\hline $\begin{array}{l}\text { Maruyama } \\
\text { et al } 1978\end{array}$ & $\begin{array}{l}\text { administration } \\
\text { orale U-[}\left[{ }^{14} \mathrm{C}\right] \mathrm{Tyr}\end{array}$ & $\begin{array}{l}\text { bréchet } \\
\text { cuisse }\end{array}$ & $\begin{array}{l}38,0 \\
24,8\end{array}$ & $\begin{array}{l}21,5 \\
23,4\end{array}$ & & & & & & $\begin{array}{c}* \\
\mathrm{~ns}\end{array}$ \\
\hline $\begin{array}{l}\text { McDonald } \\
\text { et Swick } 1891\end{array}$ & $\begin{array}{l}\text { surcharge } \\
{\left[{ }^{14} \mathrm{C}\right] \text { Val }}\end{array}$ & bréchet & 42,0 & 20,0 & & 24,0 & & 17,0 & 17,0 & nd \\
\hline $\begin{array}{l}\text { Muramatsu } \\
\text { et Okumura } 1985\end{array}$ & $\begin{array}{l}\text { surcharge } \\
{\left[{ }^{3} \mathrm{H}\right] \text { Phe }}\end{array}$ & corps & 34,0 & 31,5 & 29,7 & 25,8 & & & & $*$ \\
\hline $\begin{array}{l}\text { Saunderson } \\
\text { et Leslie } 1988\end{array}$ & $\begin{array}{l}\text { indirecte } \\
\mathrm{N}-\mathrm{MH}\end{array}$ & "muscle» & 19,2 & 14,7 & 13,1 & 11,0 & 8,3 & & & nd \\
\hline $\begin{array}{l}\text { Tesseraud } \\
\text { et al 1994a }\end{array}$ & $\begin{array}{l}\text { surcharge } \\
{\left[{ }^{3} \mathrm{H}\right] \text { Phe }}\end{array}$ & bréchet & & 22,8 & 18,3 & 12,4 & & & & $*$ \\
\hline
\end{tabular}

(1) bréchet = muscle du bréchet ; cuisse = muscle de la cuisse ; N-MH : N"-méthylhistidine

ns : non significatif ; nd : non déterminé ; ${ }^{*}$ : significatif à $\mathrm{P}<0,05$.

taux de synthèse Ks des protéines corporelles entre 1 et 4 semaines. Un résultat comparable est trouvé entre 2 et 4 semaines par Tesseraud et al (1994a) pour le Ks des protéines du muscle du bréchet (Pectoralis major). Par ailleurs, McDonald et Swick (1981) ont montré une réduction de $50 \%$ du Ks au niveau du muscle Pectoralis major entre 1 et 2 semaines, puis aucun changement significatif entre 2 et 7 semaines. Une diminution entre 1 et 2 semaines a également été mise en évidence par Maruyama et al (1978) pour le Pectoralis major, mais pas pour les muscles de la cuisse (Gastrocnemius et Peronaeus longus). L'aspect dominant de ces observations est une réduction du taux de synthèse des protéines avec l'âge, plus ou moins marquée selon les tissus mais aussi la période considérée. Cette influence de la période semble vérifiée par Muramatsu et al (1987a) qui constatent chez l'embryon une forte diminution du Ks des protéines corporelles : le Ks passe de 291 à $116 \% / \mathrm{j}$ aux $12^{\mathrm{e}}$ et 19 jours d'incubation. Cette baisse se ralentit par la suite comme le montre le graphique proposé par les mêmes auteurs à partir d'une compilation de trois de leurs études réalisées depuis le stade embryonnaire jusqu'à l'état adulte (figure 3). Signalons qu'une diminution avec l'âge du taux de synthèse est également trouvée chez les mammifères (Goldspink et Kelly 1984, Attaix et al 1988, Lobley 1993).

La capacité ribosomale Cs (ARN / Protéines) suit la même évolution que le $\mathrm{Ks}$, alors que l'activité de l'ARN reste inchangée (Muramatsu et al 1987a, Tesseraud et al 1994a, figure 4). Les variations du taux de synthèse avec l'âge sont donc expliquées par celles du potentiel de synthèse. La diminution observée de la capacité ribosomale, de forme exponentielle (figure 4), correspondrait en fait à la dilution progressive de l'ARN tissulaire par les protéines.

Lorsque la vitesse de synthèse est exprimée en valeur absolue et rapportée au poids métabolique $\left(\mathrm{kg}^{0,75}\right)$, sa diminution avec l'âge semble contestable. Muramatsu et Okumura (1985) ont les premiers mis en doute l'existence d'une telle évolution chez les poulets âgés d'une à quatre semaines. Les données de la littérature suggéraient pourtant que, chez de nombreuses espèces, la quantité de protéines synthétisées chaque jour par $\mathrm{kg}^{0,75}$ diminuait avec l'âge (compilation de Reeds et Harris 1981). Ces observations anciennes obtenues par des techniques diverses et souvent peu précises doivent faire l'objet de réserves. Les études plus récentes faites sur rongeurs (Goldspink et Kelly 1984, Obled 1988) ne montrent qu'une faible évolution en fonction de l'âge.

Figure 3. Evolution avec l'âge du taux de synthèse des protéines corporelles chez le poulet (d'après Muramatsu et al 1987a; $n=4-6$ ).

Taux de synthèse $(\% / \mathrm{j})$

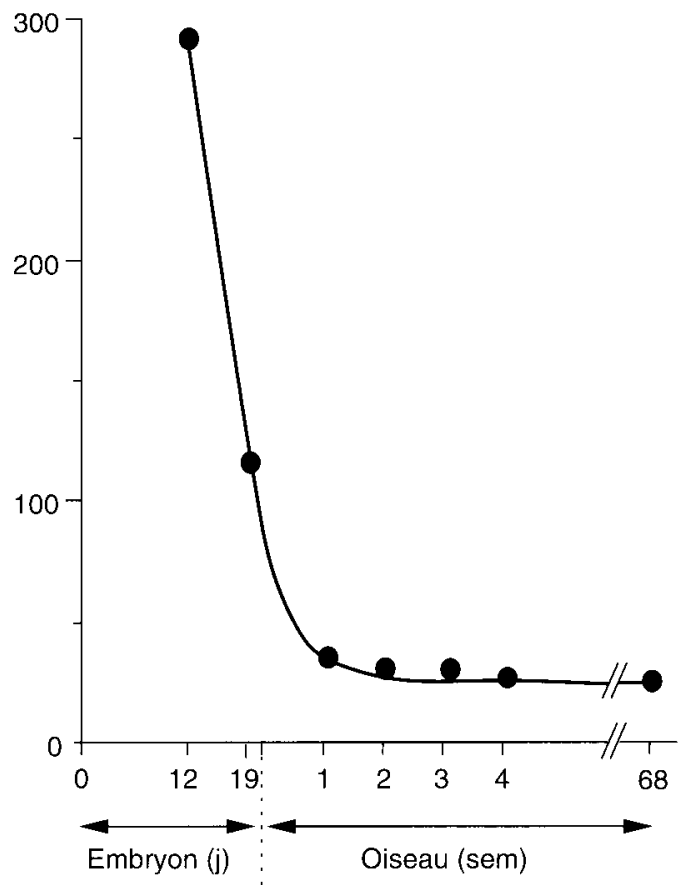


Figure 4. Evolution du taux de synthèse protéique $K s$, de la capacité ribosomale Cs et de l'efficacité traductionnelle kRNA en fonction de l'âge dans le muscle Pectoralis major du poulet (données personnelles ; $n=5-6$ ).

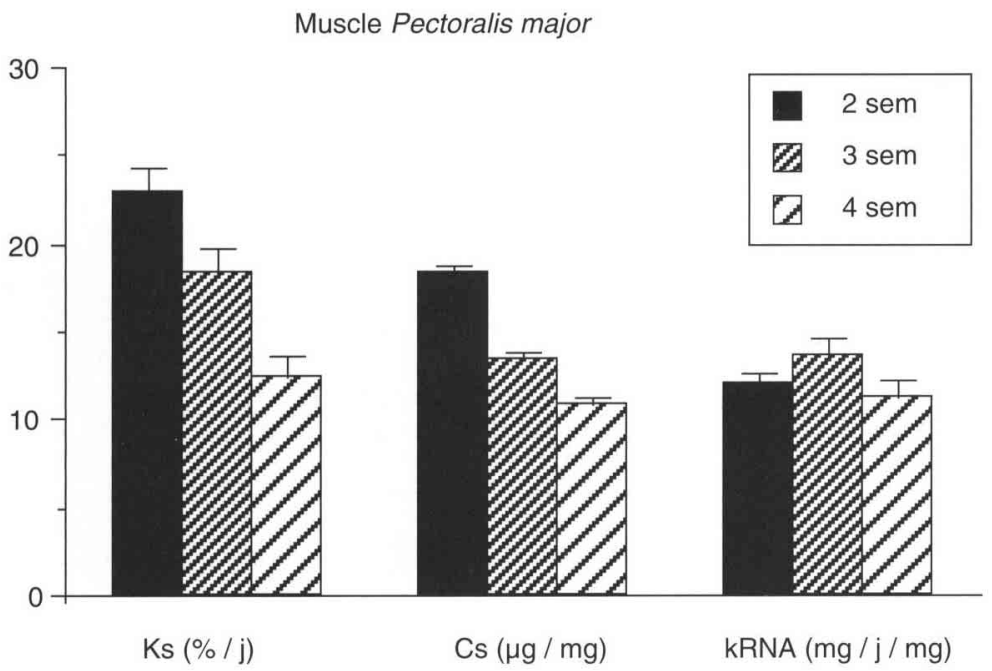

Cs $(\mu \mathrm{g} / \mathrm{mg})$

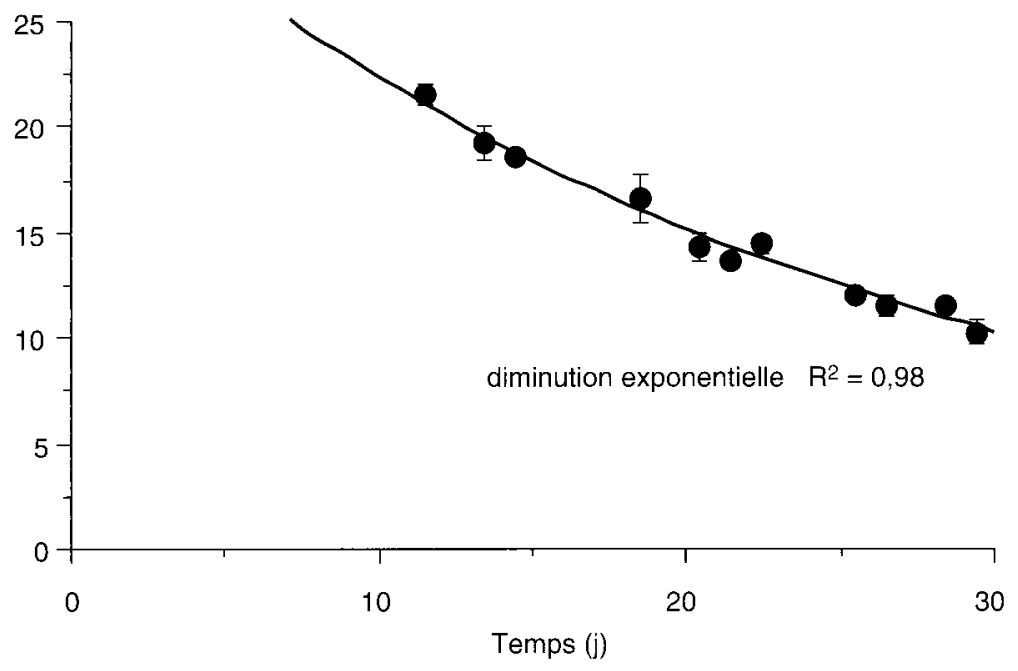

En ce qui concerne le taux de dégradation (Kd, \%/j ; tableau 2), Maruyama et al (1978) enregistrent entre une et deux semaines une diminution des valeurs de 60 et $20 \%$ pour le Pectoralis major et les muscles de la cuisse respectivement. Cette baisse importante est également observée pour la même période et pour le Pectoralis major par McDonald et Swick (1981) mais elle n'existerait plus à partir de deux semaines. Aucune variation en fonction de l'âge n'est mise en évidence au niveau du corps entier par Muramatsu et Okumura (1985), ni au niveau du muscle du bréchet par Tesseraud et al (1994a). Signalons que, pour tous ces auteurs, le Kd est estimé par différence ( $\mathrm{Kd}=\mathrm{Ks}-\mathrm{Kg}$ ). Par la mesure de l'excrétion de $\mathrm{N}^{\tau}$-méthylhistidine, Saunderson et Leslie (1988) n'enregistrent pas non plus de modification significative, même si les valeurs présentent une légère tendance à une diminution. Il semble difficile a priori de conclure sur l'évolution du taux de dégradation qui, selon les études, diminue ou reste inchangé. La diminution pourrait dépendre, comme pour le $\mathrm{Ks}$, des tissus et de la période considérée et n'exister que tôt dans le développement. Muramatsu et al (1987a) montrent d'ailleurs une baisse très importante du taux de dégradation corporelle durant la croissance embryonnaire : le Kd passe de 242 à $83 \% / j$ entre le $12^{\circ}$ et le $19^{\circ}$ jour d'incubation. Nous pensons cependant que, dans la période post-natale, si la dégradation varie avec l'âge, les variations sont faibles et de toutes façons bien moins importantes que celles de la synthèse.

\section{b / Influence du type génétique}

L'évolution rapide des souches exploitées en aviculture demande une réactualisation et parfois une remise en cause des données existantes sur le métabolisme protéique du poulet en croissance. Par exemple, au cours des dernières décennies, les poulets de chair ont été sélectionnés sur leur rendement en viande et sur leur gain de poids. Ce dernier a augmenté de $63 \%$ entre 1967 et 1986

Tableau 2. Evolution en fonction de l'âge du taux de dégradation des protéines $K d(\% / j)$ chez le poulet.

\begin{tabular}{|c|c|c|c|c|c|c|c|c|c|c|}
\hline \multirow{2}{*}{ Référence } & \multirow{2}{*}{$\begin{array}{l}\text { Méthodes } \\
\text { de mesure }\end{array}$} & \multirow{2}{*}{ Tissus (1) } & \multicolumn{7}{|c|}{ Age (semaines) } & \multirow{2}{*}{ Signif } \\
\hline & & & 1 & 2 & 3 & 4 & 5 & 6 & 7 & \\
\hline $\begin{array}{l}\text { Maruyama } \\
\text { et al } 1978\end{array}$ & $\begin{array}{l}\text { administration } \\
\text { orale } \mathrm{U}-\left[{ }^{[4} \mathrm{C}\right] \text { Tyr }\end{array}$ & $\begin{array}{l}\text { bréchet } \\
\text { cuisse }\end{array}$ & $\begin{array}{l}26,5 \\
18,0\end{array}$ & $\begin{array}{l}10,0 \\
14,2\end{array}$ & & & & & & nd \\
\hline $\begin{array}{l}\text { McDonald } \\
\text { et Swick } 1981\end{array}$ & $\begin{array}{l}\text { surcharge } \\
{\left[{ }^{14} \mathrm{C}\right] \text { Val }}\end{array}$ & bréchet & 26,0 & 10,0 & & 17,0 & & 14,0 & 13,0 & nd \\
\hline $\begin{array}{l}\text { Muramatsu } \\
\text { et Okumura } 1985\end{array}$ & $\begin{array}{l}\text { surcharge } \\
{\left[{ }^{3} \mathrm{H}\right] \text { Phe }}\end{array}$ & corps & 22,0 & 23,0 & 22,9 & 20,9 & & & & ns \\
\hline $\begin{array}{l}\text { Saunderson } \\
\text { et Leslie } 1988\end{array}$ & $\begin{array}{l}\text { indirecte } \\
\mathrm{N}^{*}-\mathrm{MH}\end{array}$ & " muscle» & 6,9 & 4,7 & 4,5 & 4,0 & 3,2 & & & ns \\
\hline $\begin{array}{l}\text { Tesseraud } \\
\text { et al 1994a }\end{array}$ & $\begin{array}{l}\text { surcharge } \\
{\left[{ }^{3} \mathrm{H}\right] \text { Phe }}\end{array}$ & bréchet & & 6,5 & 8,3 & 6,6 & & & & $\mathrm{~ns}$ \\
\hline
\end{tabular}

(1) bréchet = muscle du bréchet $;$ cuisse = muscle de la cuisse $; \mathrm{N}$-MH : N'-méthylhistidine

ns : non significatif ; nd : non déterminé. 
(source : Station Elevage Avicole, Ploufragan). Le progrès génétique annuel est actuellement de $2 \%$ pour le poids à un âge donné (soit +39 grammes par an à $41 \mathrm{j}$, en 1992). L'influence de ce type de sélection orientée sur le gain de poids, le seul que nous traiterons dans cet article, a été étudiée principalement en comparant les animaux de type chair et ceux de type ponte (sélectionnés sur des critères en rapport avec la production d'œuf) qui présentent une vitesse de croissance environ 4 fois inférieure. Quelques rares travaux ont pris pour modèles des animaux issus d'une même population et sélectionnés sur leur vitesse de croissance. Une compilation de ces résultats est présentée aux tableaux 3 et 4 .

Jones et al (1986) expliquent en partie les différences de dépôt protéique entre des poulets de type ponte ou de type chair âgés de deux semaines par un plus fort taux de synthèse protéique $\mathrm{Ks}$ dans le muscle du bréchet chez le poulet à croissance rapide $(18,5$ vs $15,9 \% / \mathrm{j}, \mathrm{P}<0,05)$. Ce résultat n'est pas retrouvé pour les muscles de la cuisse (Gastrocnemius et Peronaeus longus). D'autres travaux ont également montré des différences de synthèse entre génotypes, mais non significatives. Ainsi chez des poulets âgés de deux semaines, Maruyama et al (1978) enregistrent des taux de synthèse plus forts chez les animaux de type chair que chez ceux de type ponte : 25,8 vs $21,5 \% / j$ pour le muscle du bréchet et 25,3 vs $23,4 \%$ j pour les muscles de la cuisse (ns). De même, Saunderson et Leslie (1988) trouvent des Ks de 19,2 vs $16,2 \% / \mathrm{j}$ (type chair et type ponte respectivement, ns). Le dernier résultat présenté est obtenu à cinq jours et ne se reproduit pas pour les animaux plus âgés. Les auteurs supposent que des différences de synthèse pourraient contribuer aux différences de croissance musculaire, mais surtout à un âge inférieur à deux semaines. Cette hypothèse pourrait expliquer pour- quoi aucune différence n'est enregistrée par Hayashi et al (1985) entre animaux de souche ponte et chair âgés de 3 semaines et plus. Signalons que la comparaison d'animaux sélectionnés à partir d'une même population sur la vitesse de croissance ne montre également aucune différence significative du taux de synthèse des protéines musculaires (Johnson et al 1986, Tomas et al 1991, Tesseraud et al 1994b).

Il semble donc que la protéosynthèse ne soit que faiblement modifiée, voire inchangée par les caractéristiques génétiques. De plus les changements, lorsqu'ils existent, sont enregistrés chez de jeunes oiseaux, c'est-àdire tôt dans le développement. Il est en fait probable que la synthèse soit beaucoup plus influencée par des paramètres comme l'âge (voir plus haut) ou les facteurs nutritionnels et environnementaux, que par le type génétique (voir Tomas et al 1991 et plus loin partie 2).

L'examen des résultats de taux de dégradation obtenus par différence entre synthèse $K_{s}$ et dépôt $\mathrm{Kg}$ ou par estimation à partir de l'excrétion de $\mathrm{N}^{\top}$-méthylhistidine (tableau 4), amène à la constatation suivante: au même âge, les animaux à croissance rapide présentent le plus souvent des taux de dégradation inférieurs à ceux des animaux à croissance lente (comparaison de poulets de type chair ou ponte ou bien de lignées expérimentales sélectionnées sur la vitesse de croissance : Johnson et al 1986 et Tesseraud et al 1994b). La sélection sur la croissance modifierait donc la composante Kd du turnover protéique. Ce résultat est aussi étayé par l'existence d'une corrélation négative ( $\mathrm{P}<0,05$, régressions calculées à partir des valeurs individuelles) entre taux de dépôt $\mathrm{Kg}$ et taux de dégradation Kd (Maruyama et al 1978). Par conséquent, il semble maintenant généralement admis que cette plus faible dégrada-

Tableau 3. Influence du type génétique sur le taux de synthèse protéique $K s(\% / j)$ chez le poulet.

\begin{tabular}{|c|c|c|c|c|c|}
\hline $\begin{array}{l}\text { Souches } \\
\text { de mesure }\end{array}$ & Méthodes & $\begin{array}{r}\text { Age } \\
(\mathrm{j})\end{array}$ & $\begin{array}{l}\text { Tissus } \\
\text { (1) }\end{array}$ & Résultats & Référence \\
\hline chair/ponte & $\begin{array}{l}\text { administration } \\
\text { orale } \mathrm{C}^{-}-\left[{ }^{14} \mathrm{C}\right] \mathrm{Tyr}\end{array}$ & $\begin{array}{l}14 \\
14\end{array}$ & $\begin{array}{l}\text { bréchet } \\
\text { cuisse }\end{array}$ & $\begin{array}{l}\text { Ks : } 18,5 \text { vs } 15,9 \% \text { (chair vs ponte), } \mathrm{P}<0,05 \\
\text { pas de différence entre souches }\end{array}$ & Jones et al 1986 \\
\hline chair/ponte & $\begin{array}{l}\text { administration } \\
\text { orale, } \mathrm{U}-\left[{ }^{14} \mathrm{C}\right] \mathrm{Tyr}\end{array}$ & 14 & 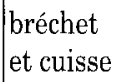 & Ks supérieurs chez la souche chair, ns & Maruyama et al 1978 \\
\hline chair/ponte & indirecte, $\mathrm{N}^{\mathrm{r}}-\mathrm{MH}$ & $\begin{array}{c}5 \\
10-30\end{array}$ & «muscle» & $\begin{array}{l}\text { Ks : } 19,2 \mathrm{vs} 16,2 \% / \mathrm{j} \text { (chair vs ponte), ns, } \\
\text { pas de différence entre souches }\end{array}$ & $\begin{array}{l}\text { Saunderson et Leslie } \\
1988\end{array}$ \\
\hline chair/ponte & $\begin{array}{l}\text { surcharge, } \\
{\left[{ }^{3}\right] \text { Phe }}\end{array}$ & 14 & corps & pas de différence entre souches & $\begin{array}{l}\text { Muramatsu et al } \\
1987 \mathrm{e}\end{array}$ \\
\hline chair/ponte & indirecte, $\mathrm{N}^{ }-\mathrm{MH}$ & $\begin{array}{c}21 \\
42 ; 63\end{array}$ & «muscle " & pas de différence entre souches & Hayashi et al 1985 \\
\hline expérimentales & $\begin{array}{l}\text { indirecte, } \mathrm{N}^{\mathrm{t}} \mathrm{MH} \\
\text { Surcharge, } \\
{\left[{ }^{3} \mathrm{H}\right] \text { Phe }}\end{array}$ & $\begin{array}{c}14 ; 42 \\
42\end{array}$ & $\begin{array}{l}\text { "muscle " } \\
\text { muscles }\end{array}$ & pas de différence entre lignées & $\begin{array}{l}\text { Tomas et al } 1991 \\
\text { Johnson et al } 1986\end{array}$ \\
\hline expérimentales & $\begin{array}{l}\text { surcharge, } \\
{\left[{ }^{3} \mathrm{H}\right] \text { Phe }}\end{array}$ & $14 ; 28$ & bréchet & pas de différence entre lignées & Tesseraud et al 1994b \\
\hline
\end{tabular}

(1) bréchet $=$ muscle du bréchet $;$ cuisse $=$ muscles de la cuisse $; N^{⿰}$-méthylhistidine. ns $:$ non significatif. 
Tableau 4. Influence du type génétique sur le taux de dégradation protéique $K d(\% / j)$ chez le poulet.

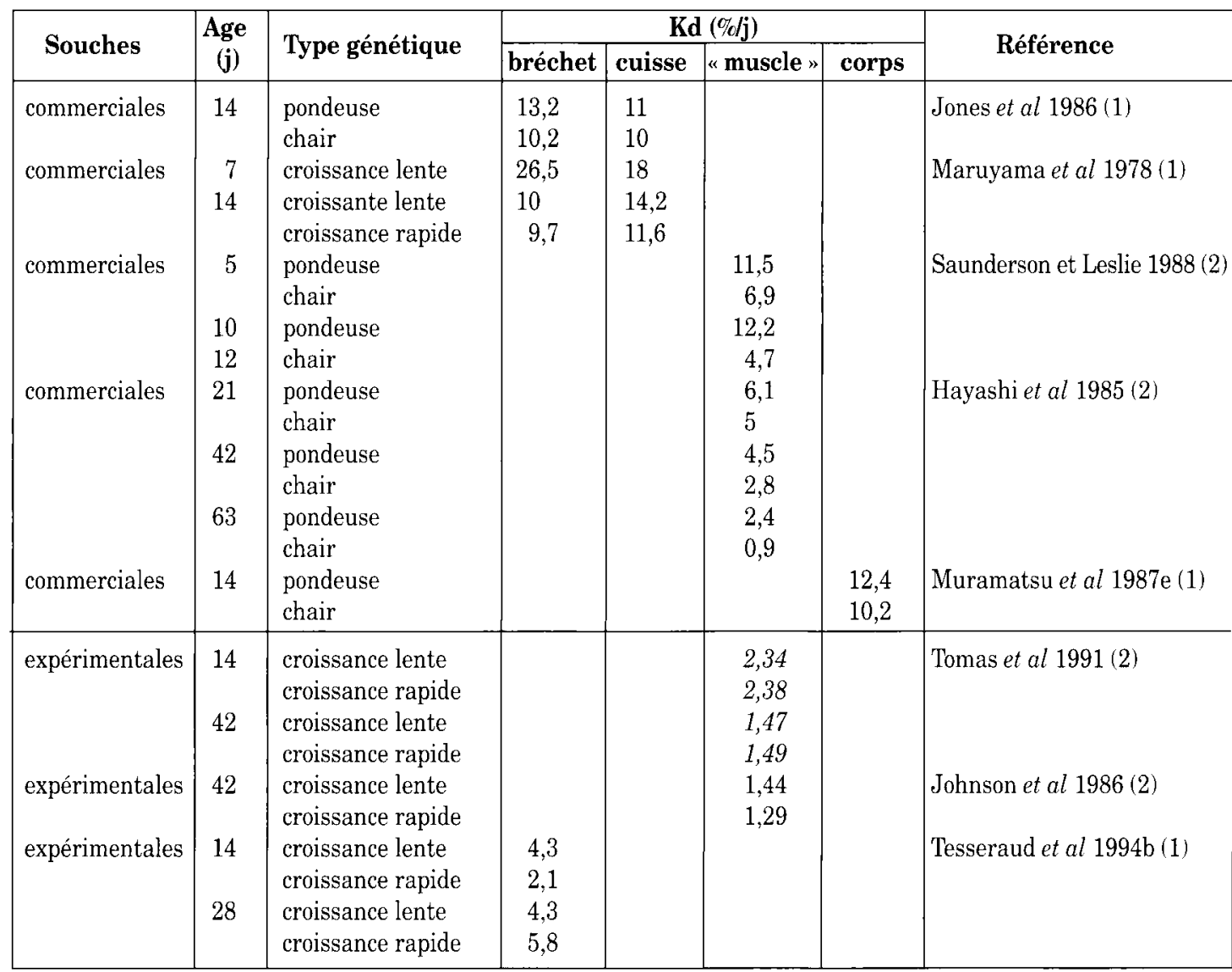

(1) Calcul par différence $\mathrm{Kd}=\mathrm{Ks}-\mathrm{Kg}$; (2) estimation à partir de l'excrétion de N-méthylhistidine (N-MH). Les valeurs de Kd en italique ont été calculées à partir de données d'excrétion de $\mathrm{N}-\mathrm{MH}(\mu \mathrm{mol} / \mathrm{mol} \mathrm{N}$ de la carcasse $/ \mathrm{j})$ en prenant comme teneur en $\mathrm{N}^{\mathrm{t}}$ MH de la carcasse la valeur de $234 \mu \mathrm{mol} / \mathrm{mol} \mathrm{N}$ obtenue par Tomas et al 1988 chez les mêmes lignées ; bréchet = muscle du bréchet ; cuisse $=$ muscles de la cuisse.

tion mesurée chez les poulets à croissance rapide soit le facteur expliquant la différence de dépôt protéique entre génotypes (voir également la revue de Griffin et Goddard 1994).

En conclusion, synthèse et dégradation protéique, les deux paramètres qui régissent la fixation des protéines chez l'animal en croissance, sont fortement influencées par les facteurs liés à l'animal. Rappelons en particulier le déclin du taux de protéosynthèse avec l'âge. Enfin, le taux de dégradation parait être le facteur important dans la régulation génétique du dépôt protéique.

\section{2 / Effets des apports protéiques}

Les facteurs alimentaires ont des effets multiples sur le métabolisme protéique, classiquement divisés en effets à court terme, observés en période post-prandiale, et effets à plus long terme, spécifiques du régime alimentaire et faisant intervenir la composition et l'abondance des nutriments. Nous ne parlerons pas ici des variations à court terme liées à la distribution du repas. En effet, le poulet, particulièrement quand il est jeune, consomme généralement son aliment tout au long de la journée. L'apport de nutriments serait donc relativement continu avec un état pseudo-stationnaire du turnover protéique (Muramatsu 1990). Nous présenterons ici l'effet des apports quantitatifs et qualitatifs en nutriments, en nous limitant aux protéines.

\section{1 / Protéines alimentaires}

Comme le soulignent McNurlan et Garlick (1989), deux questions sont posées : comment la nature du régime affecte-t-elle la réponse métabolique et comment l'état nutritionnel influence-t-il la réponse à un régime particulier? Nous traiterons chacun de ces deux aspects.

\section{a / Apport d'une quantité variable de protéines}

- Métabolisme protéique au niveau du corps entier

Le besoin en protéines est en général déterminé comme étant le niveau d'apport permettant la croissance maximale ou le dépôt pro- 
Figure 5. Courbes dose-réponses entre ingéré protéique et gain de poids, dépôt protéique et synthèse des protéines corporelles obtenues chez le jeune poulet (d'après Muramatsu et al 1987b).

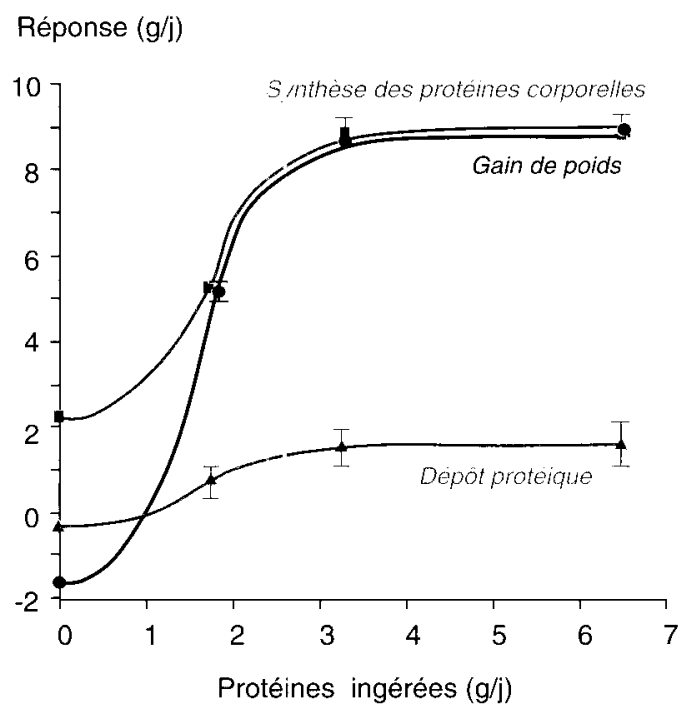

téique le plus élevé. Chez le poulet en croissance, la vitesse de synthèse des protéines au niveau du corps entier exprimée en termes de taux $(\% / j)$ ou de valeur absolue $(g / j)$ augmente significativement avec les quantités croissantes de protéines dans le régime jusqu'à la valeur de $200 \mathrm{~g}$ de protéines par kg d'aliment (Muramatsu et al 1987b). Au dessus de cette valeur correspondant à peu près au besoin, aucune augmentation supplémentaire n'est observée.

Dans une revue récente, Muramatsu (1990), reprenant des travaux réalisés par son équipe sur le jeune poulet, examine plus en détail les relations entre l'ingéré protéique et les paramètres suivants : croissance, dépôt protéique et enfin synthèse des protéines corporelles. La réponse de chacune de ces variables aux variations d'apport protéique présente des courbes sigmoïdes similaires (figure 5). Environ $3 \mathrm{~g}$ de protéines par jour permettent d'atteindre $90 \%$ des valeurs maximales, ce qui correspond à la recommandation journalière d'apport protéique pour une croissance maximum chez des oiseaux de cet âge (régime contenant $20 \%$ de protéines).

Un excès de protéines a un effet contraire sur la synthèse des protéines corporelles. Kita et al (1989a) ont nourri de jeunes poulets avec des régimes contenant 20,40 et $60 \%$ de protéines. Ils observent une diminution significative de la vitesse de la protéosynthèse avec l'augmentation de l'apport protéique (synthèse en $\mathrm{g} / \mathrm{j}=6,6 ; 6,4$ et 5,2 pour 20,40 et $60 \%$ de protéines dans le régime respectivement; la moyenne pour $60 \%$ de protéines est significativement différente des deux autres, $\mathrm{P}<0,05$ ). Le taux de synthèse $(\mathrm{Ks}, \% / \mathrm{j})$ diminue également mais sans atteindre la signification statistique. Ces auteurs suggèrent que la réduction de la synthèse protéique corporelle avec un excès de protéines peut être liée à une modification de l'équilibre hormonal. Ainsi, le glucagon dont la concentration plasmatique est augmentée par des régimes riches en protéines inhibe, entre autres, la synthèse de l'albumine dans le foie. Il faut toutefois nuancer son effet sur le métabolisme protéique car le glucagon peut aussi stimuler, dans le même organe, la synthèse de protéines particulières comme les enzymes de la gluconéogénèse hépatique.

Dans toutes les études décrites ci-dessus, les auteurs ont travaillé avec des régimes isoénergétiques distribués ad libitum. Or la consommation d'aliment diminue lorsque l'apport de protéines est soit excessif (régimes contenant 40 ou $60 \%$ de protéines), soit nul ( $0 \%$ de protéines). Certaines expériences ont donc été réalisées en administrant à tous les animaux, quel que soit le lot, une quantité fixée de nourriture (repas égalisés = "pairfeeding "), de manière à éliminer tout changement d'apport de nutriments autre que les protéines. Dans ces conditions, la réponse de la protéosynthèse face à une augmentation des apports protéiques reste similaire à celle décrite avec les régimes ad libitum jusqu'au régime contenant $20 \%$ de protéines, alors qu'elle diminue significativement entre 20 et $40 \%$ de protéines (Muramatsu et al 1987b). Cette baisse est confirmée par Kita et al (1989a) pour la même plage de variation des apports protéiques. Il n'y aurait pas de diminution supplémentaire entre 40 et $60 \%$ de protéines dans le régime. L'utilisation de la technique dite de repas égalisés, si elle permet a priori de n'étudier que l'effet des protéines, présente cependant quelques limites. Muramatsu et al (1987b) signalent que, dans leur étude, le pair-feeding rend difficile la distribution d'une quantité suffisante de nourriture : les oiseaux peuvent être carencés aussi bien en énergie qu'en protéines. Or un déficit en énergie peut restreindre la croissance et diminuer la protéosynthèse corporelle des animaux (Kita et al 1989b, Muramatsu 1990). Cet aspect - effet des contenus respectifs en énergie et protéines - ne sera pas analysé dans cet article. Il a été étudié en détail par Kita et al (1993) à l'aide d'une approche facto-

Figure 6. Surface de réponse de la vitesse de synthèse des protéines corporelles à des ingérés protéiques et énergétiques variables chez des poulets (d'après Kita et al 1993).

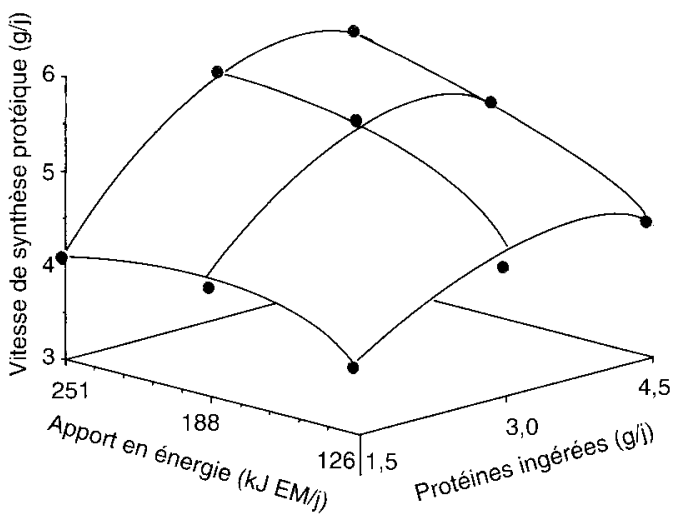


rielle et nous avons schématisé la surface de réponse de la vitesse de synthèse des protéines corporelles face à des ingérés protéiques et énergétiques variables à la figure 6. Par ailleurs, cette technique de pair-feeding appliquée avec seulement deux repas par jour conduit à faire varier l'état nutritionnel au cours de la journée. Il existe alors une alternance de phases de repas et de jeûne entre les repas pendant lesquelles le métabolisme protéique est modifié. En particulier, une augmentation rapide de la protéosynthèse se produit en réalimentant des poulets après $48 \mathrm{~h}$ de jeûne (Aoyagi et al 1990).

La vitesse de dégradation des protéines corporelles (en $\mathrm{g} / \mathrm{j}$ ) évolue en fonction de l'apport protéique de la même manière que la vitesse de protéosynthèse, mais l'amplitude de variation est moindre (Muramatsu et al 1987b). Ce phénomène est observé pour les deux modes de distribution des aliments (ad libitum ou pair-feeding). Les auteurs concluent donc que l'adaptation du turnover des protéines corporelles aux variations de la quantité de protéines ingérées s'effectue principalement par des changements de la synthèse protéique. laire

- Métabolisme protéique au niveau tissu-

A notre connaissance, il n'existe que très peu d'études chez le poulet en croissance permettant de rendre compte des modifications du turnover protéique induites par des apports en protéines variables au niveau des tissus individuels. Kita et Okumura (1993) montrent que la synthèse fractionnaire ou absolue des protéines du muscle du bréchet (Pectoralis major) est identique pour des régimes isoénergétiques contenant 20 et $40 \%$ de protéines (apports au dessus du besoin) et distribués ad libitum. Ils concluent que la protéosynthèse musculaire ne serait pas affectée par un excès de protéines, dans la mesure où l'apport d'énergie métabolisable est suffisant pour couvrir le besoin des animaux. En revanche, dans le foie, le taux de synthèse ( $\mathrm{Ks}$ en \%/j) diminue de $28 \%$ chez les poulets nourris avec un régime riche en protéines comparé à l'aliment témoin (40 vs $20 \%$ de protéines). Cette baisse est parfaitement expliquée par la réduction de la capacité ribosomale $(-25 \%)$, donc par une modification du potentiel de synthèse, puisque l'efficacité ribosomale (ou traductionnelle) reste constante. Ceci n'entraîne pourtant pas de changement significatif de la vitesse absolue de synthèse des protéines hépatiques puisque la distribution du régime riche en protéines a augmenté la quantité de protéines dans le foie (hypertrophie hépatique et augmentation de la teneur en protéines du foie).

La privation totale de protéines diminue significativement le $\mathrm{Ks}$ et la capacité ribosomale dans le muscle du bréchet (Muramatsu et al 1985), alors qu'elle augmente le taux de dégradation $\mathrm{Kd}$. Lorsque les résultats sont exprimés en valeur absolue $(\mathrm{g} / \mathrm{j})$, la protéosynthèse comme la protéolyse sont réduites, avec une baisse plus importante pour la syn- thèse. Au niveau du foie, la distribution d'un régime protéiprive entraîne, comme dans le muscle, une baisse du taux et de la vitesse de synthèse ainsi que de la capacité ribosomale (Muramatsu et al 1983). Chez le poulet, nous ne disposons d'aucune information concernant l'évolution des intensités du turnover des protéines tissulaires suite à des variations de l'ingéré protéique pour des apports inférieurs ou proches du besoin. Signalons que chez le porcelet, un doublement de l'apport protéique (régimes contenant 15 et $30 \%$ de protéines) augmente le $\mathrm{Ks}$ des protéines du muscle Semitendinosus et du foie (Seve et al 1986).

\section{b / Restriction puis réalimentation protéique}

Les seules études disponibles chez le poulet sont relativement anciennes (Maruyama et al 1978, McDonald et Swick 1981). Nous présenterons donc aussi des résultats obtenus chez la poule pondeuse (Muramatsu et al 1987c et d).

En 1981, McDonald et Swick ont utilisés des traitements alimentaires entraînant une atrophie musculaire suivie d'une croissance rapide, soit une déplétion puis réplétion protéique. Ils montrent que le poulet âgé de 4 semaines nourri avec un régime protéiprive pendant 17 jours, perd en moyenne $30 \%$ de son poids initial et $66 \%$ de protéines dans le muscle Pectoralis major. Cette perte protéique importante serait propre au muscle du bréchet dont le développement est un "produit » de la sélection génétique et qui possède une faible utilité fonctionnelle dans cette espèce. Elle s'accompagne d'une diminution des quantités de protéines synthétisées et dégradées par jour ; l'atrophie musculaire est due à la baisse de l'intensité de synthèse plus marquée que celle de la protéolyse.

Le remplacement de ce régime protéiprive par un régime témoin permet d'obtenir une croissance rapide (phase dite de récupération) avec une augmentation des quantités de protéines synthétisées et, dans une moindre mesure, de celles dégradées. Le taux de synthèse double en 2 jours, résultat d'un accroissement de l'activité de l'ARN, alors que le taux de dégradation n'est pas modifié. Ce sont donc les modifications du taux de synthèse protéique qui provoquent des changements de la masse protéique du muscle du bréchet lors de la déplétion et la réplétion protéiques. Cette observation va à l'encontre de résultats antérieurs (Maruyama et al 1978): lors de restrictions alimentaires modérées imposées à des poulets d'une semaine, l'accélération de la croissance musculaire associée à la récupération (principalement au niveau du muscle du bréchet), était liée à une réduction du taux de la dégradation protéique. McDonald et Swick suggèrent 3 explications à ces résultats contradictoires : (1) les taux de synthèse et de dégradation protéique peuvent être modifiés différemment selon la sévérité de la restriction ali- 
mentaire ; (2) la réponse à une restriction alimentaire peut dépendre de l'âge de l'animal ; (3) la diminution des taux de synthèse et de dégradation, liée à l'âge, complique l'interprétation des expériences lorsque des restrictions alimentaires sont imposées à l'âge d'une semaine. Il serait possible de répondre à cette dernière interrogation en effectuant les mesures non seulement à âge constant mais aussi à poids constant.

En ce qui concerne la poule pondeuse, les premiers effets constatés d'une carence en protéines sont les diminutions du poids corporel, de l'ingéré alimentaire et de la rétention protéique, le bilan azoté devenant même négatif (Muramatsu et al $1987 \mathrm{c}$ et d). Tous ces paramètres augmentent après réalimentation protéique pour atteindre à peu près le niveau initial. Etudiant le turnover protéique, Muramatsu et al (1987c) montrent une diminution des vitesses de synthèse et de dégradation des protéines corporelles après la distribution pendant 7 jours d'un régime protéiprive. Ces valeurs sont restaurées complètement après réalimentation pendant $7 \mathrm{j}$ avec un régime commercial. L'étude quotidienne des composantes du turnover protéique (Muramatsu et al 1987d) fait apparaître une diminution rapide de la vitesse de synthèse des protéines corporelles, puis un plateau est atteint après $7 \mathrm{j}$ de carence en protéines (figure 7). La réponse de la vitesse de dégradation est similaire mais moins prononcée. Il est intéressant de constater que près de la moitié de la réduction de la protéosynthèse corporelle provoquée par la carence en protéines est due à une diminution des synthèses dans l'oviducte et, dans une moindre mesure, dans le foie. La réalimentation protéique accélère le turnover des protéines en augmentant surtout la vitesse de synthèse avec un changement moins marqué de la vitesse de protéolyse. Ces activités métaboliques s'accroissent plus rapidement pendant les 2 premiers jours jusqu'à atteindre des valeurs stables après $7 \mathrm{j}$, valeurs alors égales à celles trouvées au début de l'expérience.

Il semble donc que les variations du niveau des apports protéiques influencent le turnover protéique principalement en modifiant la protéosynthèse. La dégradation suit une évolution similaire mais de moins grande amplitude.

\section{2 / Composition en acides aminés}

Il est important dans un premier temps de rappeler pourquoi nous nous intéressons aux acides aminés alimentaires et pourquoi nous voulons maîtriser la composition en acides aminés des régimes destinés aux poulets en croissance. Les objectifs recherchés sont de limiter les gaspillages de protéines et d'acides aminés, donc de diminuer les pertes d'azote (problème de pollution) en ayant un dépôt protéique maximum. Chaque acide aminé doit être apporté en quantité suffisante, en évitant les carences mais aussi les excès (notion d'équilibre entre acides aminés). Deux sortes d'expériences ont été réalisées pour étudier l'effet d'acides aminés alimentaires particuliers sur le métabolisme protéique : dans les premières, il s'agit d'analyser l'effet d'un apport d'un acide aminé particulier avec un régime protéiprive; dans les secondes, d'examiner l'effet de la carence en un acide aminé dans un régime bien équilibré par ailleurs.

\section{a / Addition d'un acide aminé dans un régime protéiprive}

L'addition de méthionine à un régime protéiprive réduit la perte de poids et améliore le bilan azoté (Muramatsu et Okumura 1979a). Cet effet d' "épargne d'azote " produit par la méthionine est augmenté par l'addition simultanée d'arginine, alors que les autres acides aminés restent inefficaces. De plus, Muramatsu et Okumura (1979b) constatent que la supplémentation en méthionine plus arginine (MA) diminue l'excrétion d'acide urique. Il semble que cet effet d'épargne dû à l'apport de MA soit surtout marqué dans le muscle (Muramatsu et Okumura 1979c). Ce tissu serait donc celui qui contribue le plus à l'amélioration de la balance azotée chez les poulets carencés en protéines mais supplémentés en MA.

L'addition de méthionine seule (M) ou avec de l'arginine (MA) augmente les intensités des 2 composantes du turnover protéique corporel (Muramatsu et al 1986). L'effet est significatif pour la vitesse de synthèse des protéines exprimée à la fois en pourcentage et en valeur absolue. La vitesse de dégradation (en valeur absolue) augmente, mais dans une moindre mesure que la protéosynthèse, le

Figure 7. Effet de la restriction puis de la réalimentation protéique sur le turnover des protéines corporelles de la poule pondeuse (d'après Muramatsu et al 1987d).

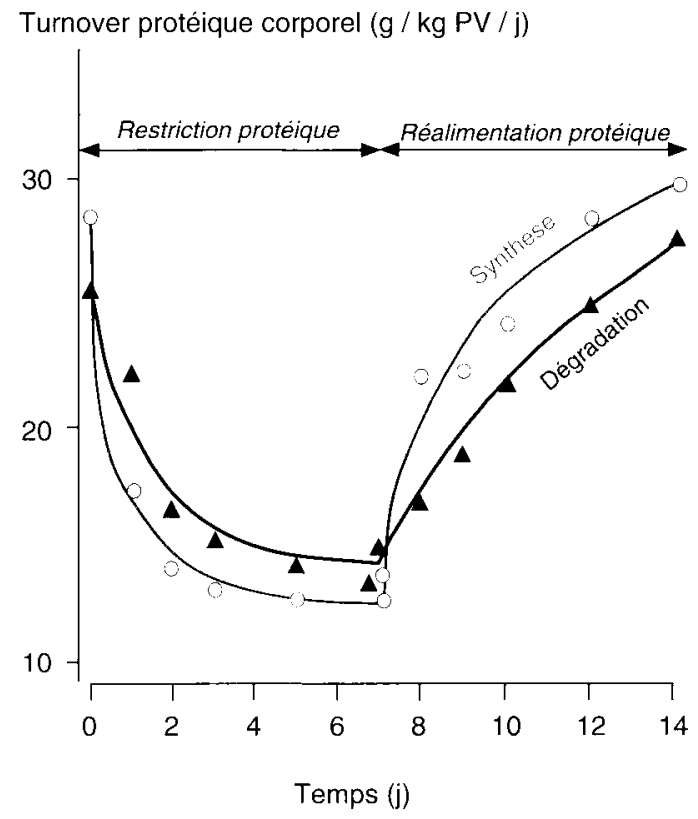


taux de la protéolyse $(\% / j)$ restant même inchangée. Ces valeurs de protéosynthèse plus élevées au niveau du corps entier expliqueraient, selon ces auteurs, l'effet d'épargne d'azote provoqué par l'addition de $\mathrm{M}$ ou MA. Cet effet est également observé dans le jejunum, probablement dans le foie (Muramatsu et al 1983), et même de manière plus importante dans le muscle squelettique (Muramatsu et al 1985). L'augmentation du taux de synthèse serait expliquée par une plus forte activité ribosomale mesurée au niveau du corps entier ou du muscle squelettique (Muramatsu et al 1985 et 1986), suggérant une régulation traductionnelle.

Le phénomène d'épargne d'azote constaté ci-dessus peut paraître surprenant puisqu'il n'y a pas d'acide aminé dans le régime si on excepte la méthionine et l'arginine. L'augmentation du rapport entre la synthèse protéique et le flux (c'est-à-dire la perte plasmatique du composé marqué ; cf figure 1), suggère une amélioration de la réutilisation des acides aminés endogènes résultant de la dégradation des protéines corporelles, puisque dans cette étude la contribution des acides aminés alimentaires est négligeable par rapport au flux (Muramatsu et al 1986). En fait, chez les animaux nourris avec un régime protéiprive, les acides aminés provenant de la protéolyse seraient, d'après Muramatsu (1990), déficients en méthionine en comparaison des besoins pour la synthèse. Il faut en effet tenir compte des sources de perte en méthionine. Premièrement, la méthionine serait probablement oxydée plus rapidement que les autres acides aminés (Kino et Okumura 1987b). Deuxièmement, les acides aminés soufrés (méthionine et cystine) sont incorporés en quantité importante dans les protéines des plumes (au moins $10 \%$ de cystine dans les protéines). Ces protéines, une fois synthétisées, ne peuvent libérer leurs acides aminés qui ne réapprovisionnent donc pas le pool des acides aminés libres. En cas d'une privation de protéines pendant laquelle la croissance des plumes et la synthèse de leurs protéines existent toujours (Muramatsu et Okumura 1979c), les besoins en acides aminés seraient donc encore accentués. Ceci rendrait nécessaire un accroissement de la dégradation protéique tissulaire et le muscle constituerait, selon ces auteurs, la source principale de ces acides aminés pour permettre la croissance des plumes.

En conclusion, quelle que soit la raison de l'effet d'épargne d'azote, l'atténuation de la déficience en un acide aminé essentiel particulier, la méthionine, entraînerait une augmentation du turnover protéique chez le poulet, même lorsqu'il est soumis à une carence totale en protéines.

\section{b / Carence ou supplémentation en un acide aminé essentiel}

Nous raisonnerons essentiellement en termes de carence en un acide aminé. En effet, dans la littérature, c'est en général l'absence ou l'insuffisance qui sont étudiées en référence à un régime témoin équilibré plutôt que la supplémentation elle-même.

La distribution à des poulets d'un régime carencé en un acide aminé diminue leurs performances de croissance, leur consommation et leur bilan azoté, ce dernier pouvant même devenir négatif (Akinwande et Bragg 1985, Okumura et al 1985, Kino et Okumura 1986a et b). Signalons que selon Kino et Okumura (1986a), la sévérité de la carence en un acide aminé ne dépendrait pas seulement du degré de la déficience mais serait aussi fonction de l'acide aminé. Ils ont donc proposé de regrouper les acides aminés en 4 groupes : un premier groupe formé d'acides aminés à faible effet (histidine, lysine et tryptophane), un deuxième constitué de leucine, phénylalanine

Figure 8. Effet de la carence en lysine sur les intensités du turnover des protéines du muscle Pectoralis major de poulets âgés de 2, 3 et 4 semaines (Tesseraud et al 1994a; $n=5-7$ ). Synthèse = dépôt + dégradation. $T$ : témoin, $L(-)$ : carencé en lysine, * différent du témoin $(P<0,05)$.



âge (semaines)

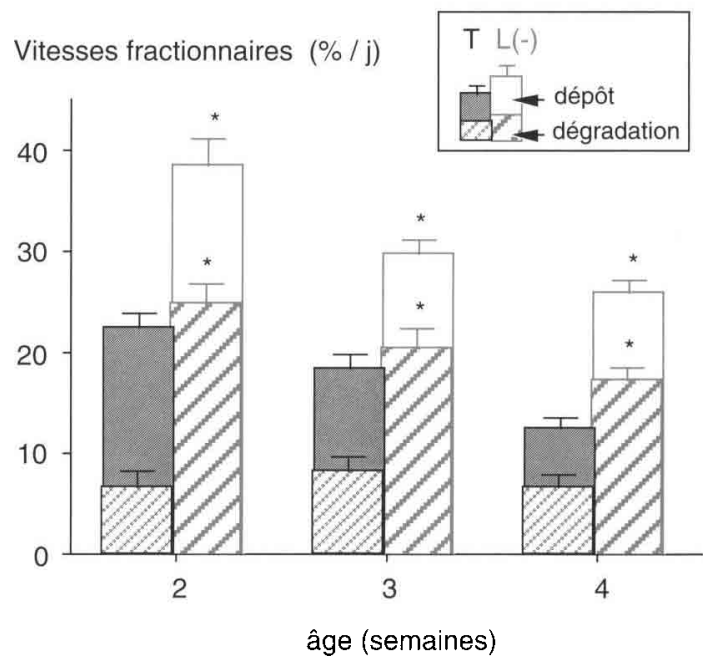


et tyrosine, un troisième avec thréonine, valine, arginine, isoleucine et un dernier comprenant méthionine et cystine, à fort effet.

La diminution du bilan azoté lors d'une carence en un acide aminé, comme la lysine (Tesseraud et al 1992 et 1994a), l'histidine ou les acides aminés soufrés (Kino et Okumura 1987a), s'accompagne principalement d'une baisse des quantités de protéines synthétisées (figure 8 ). Ces résultats obtenus chez le poulet en croissance concordent avec ceux trouvés chez la poule pondeuse par Hiramoto et al (1990) : la carence en lysine ou en méthionine réduit la synthèse protéique au niveau du corps entier et des tissus impliqués dans la formation des protéines de l'œuf (foie et surtout oviducte). Ils sont également en accord avec différentes études de carence en lysine réalisées chez les mammifères. Salter et al (1990) montrent en effet des résultats identiques chez le porc en croissance. Conway et al (1980) et Meredith et al (1986) enregistrent une réduction des vitesses du turnover protéique chez l'homme. La seule conclusion différente est obtenue par Fuller et al (1987) qui observent, chez le porc en croissance nourri avec un régime déficient en lysine, une baisse du dépôt sans changement net ou significatif de la protéosynthèse et de la protéolyse corporelles.

Les résultats des études de Kino et Okumura (1987a) et de Tesseraud et al (1992 et 1994a) divergent cependant lorsqu'ils sont exprimés en termes de taux $(\% / j)$. En cas de carence absolue en acides aminés soufrés ou en histidine, Kino et Okumura enregistrent une diminution des taux de synthèse corporelles, ceux de dégradation restant constants, alors que nous observons avec un déficit de lysine, une augmentation des taux de synthèse et de dégradation musculaires (figure 8). Plusieurs raisons peuvent être évoquées pour expliquer les divergences.

D'abord, l'effet d'une carence en acide aminé dépend probablement de l'acide aminé déficient dans le régime. Ainsi Kino et Okumura (1987a) enregistrent un effet plus marqué avec des aliments dépourvus d'acides aminés soufrés qu'avec ceux sans histidine. Ceci pourrait être dû au rôle particulier joué par la méthionine dans la synthèse protéique. En effet, l'initiation de la traduction peut être inhibée par une carence en cet acide aminé puisqu'elle consiste en la fixation sur la petite sous unité du ribosome (40 S) d'un complexe ternaire formé par l'elF 2 (eucaryotic initiation factor 2), le GTP et le méthionyl ARNt (ARN de transfert portant la méthionine) (voir la revue de Kimball et Jefferson 1988 pour plus de détails sur l'initiation de la synthèse protéique). Cependant, une absence en un acide aminé essentiel (lysine, tyrosine, tryptophane ou méthionine) peut aussi inhiber la formation du complexe ternaire en augmentant la phosphorylation de $\mathrm{eIF}_{2} \alpha$ (Everson et al 1989).

Ensuite les taux de synthèse et de dégradation peuvent également varier différemment selon la sévérité de la restriction, comme suggéré par McDonald et Swick (1981) à propos des protéines.

La réponse à une carence en acide aminé pourrait aussi dépendre des génotypes utilisés (poulets Leghorn à croissance lente ou Shaver à croissance rapide). Cette hypothèse est suggérée par l'existence de différences d'utilisation et de besoins en acides aminés soufrés chez des lignées génétiquement maigres et grasses (Leclercq et al 1993). A notre connaissance, aucune information n'est disponible dans la littérature concernant la sensibilité respective de poulets à vitesses de croissance différentes à la carence en acides aminés. Cependant, il est admis que leur métabolisme protéique basal diffère, comme nous l'avons déjà précisé dans la première partie de cet article.

Enfin, les résultats peuvent dépendre du lieu de mesure du turnover protéique, corps entier ou tissus particuliers.

En résumé, de nombreuses incertitudes demeurent dans la compréhension de l'effet d'une carence en un acide aminé sur le métabolisme protéique. Des conditions expérimentales différentes entre études pourraient expliquer certaines données contradictoires. Des progrès prévisibles devraient reposer en particulier sur une meilleure connaissance des différences d'effet de la carence pouvant exister entre tissus. De plus, sachant que les acides aminés ont une action directe en tant que substrat et indirecte via les hormones, il nous semble aussi important de pouvoir préciser quelle peut être la régulation hormonale. Nous avons d'ailleurs déjà mis clairement en évidence dans des travaux réalisés sur mammifères une interaction entre les effets de l'insuline et des acides aminés sur le métabolisme protéique (Tesseraud et al 1993).

\section{Conclusion}

Chez le poulet en croissance, le renouvellement protéique varie fortement avec l'âge (diminution du taux de synthèse) et avec le génotype (plus faible taux de dégradation chez des poulets à croissance rapide). La diminution de l'apport d'un acide aminé comme celle des apports protéiques, réduit les quantités de protéines déposées. Ceci est principalement dû à une baisse de la vitesse de protéosynthèse. Cependant, des études supplémentaires sont encore nécessaires pour approfondir les mécanismes de la diminution du dépôt protéique. Il paraît notamment important pour explorer correctement le rôle des acides aminés d'y associer la médiation par les hormones.

\section{Remerciements}

Nous tenons à remercier A.M. Chagneau et M. Plouzeau pour leur participation à l'élaboration de cette revue, ainsi que J.-C. Blum pour ses conseils et suggestions. 


\section{Références bibliographiques}

Akinwande A.I., Bragg D.B., 1985. Effect of the level of dietary lysine on turnover rate of liver protein in the chick. Poult. Sci., 64, 1938-1940.

Aoyagi Y., Muramatsu J., Okumura J., 1990. Contribution of whole-body protein synthesis to diet-induced thermogenesis in chicks. Nutr. Research, 10, 627-634.

Arnal M., Obled C., Attaix D., Patureau Mirand P., Bonin D., 1987. Dietary control of protein turnover. Diabete Metabolism (Paris), 13, 630-642.

Attaix D., Manghebati A., Grizard J., Arnal M., 1986. Assessment of in vivo protein synthesis in lamb tissues with $\left[{ }^{3} \mathrm{H}\right]$ valine flooding doses. Biochim. Biophys. Acta, 882, 389-397.

Attaix D., Aurousseau E., Bayle G., RosolowskaHuszcz D., Arnal M., 1988. Respective influence of age and weaning on skeletal and visceral muscle protein synthesis in the lamb. Biochem. J., 256, 791795 .

Conway J.M., Bier D.M., Motil K.J., Burke J.F., Young V.R., 1980. Whole-body lysine flux in young adult men : effects of reduced total protein and of lysine intake. Am. J. Physiol., 239, E192-200.

Everson W.V., Flaim K.E., Susco D.M., Kimball S.R., Jefferson L.S., 1989. Effect of amino acid deprivation on initiation of protein synthesis in rat hepatocytes. Am. J. Physiol., 256, C18-27.

Fuller M.F., Reeds P.J., Cadenhead A., Seve B., Preston T., 1987. Effect of the amount and quality of dietary protein on nitrogen metabolism and protein turnover of pigs. Br. J. Nutr., 58, 287-300.

Garlick P.J., McNurlan M.A., Preedy V.R., 1980. A rapid and convenient technique for measuring the rate of protein synthesis in tissues by injection of $\left[{ }^{3} \mathrm{H}\right]-$ Phe. Biochem. J., 192, 719-723.

Garlick P.J., McNurlan M.A., Essen P., Wernerman J., 1994. Measurement of tissue protein synthesis rates in vivo: critical analysis of contrasting methods. Am. J. Physiol., 266, E287-297.

Goldspink D.F., Kelly F.J., 1984. Protein turnover and growth in the whole-body, liver and kidney of the rat from the fœtus to the senility. Biochem. J., $217,507-516$

Griffin H.D., Goddard C., 1994. Rapidly growing broiler (meat-type) chickens : their origin and use for comparative studies of the regulation of growth. Intern. J. Biochem., 26, 19-28.

Hayashi K., Tomita Y., Maeda Y., Shinagawa Y. Inoue K., Hashizume T., 1985. The rate of degradation of myofibrillar proteins of skeletal muscle in broiler and layer chickens estimated by $\mathrm{N}^{\tau}$-methylhistidine in excreta. Br. J. Nutr., 54, 157-163.

Hiramoto K., Muramatsu T., Okumura J., 1990. Effect of methionine and lysine deficiencies on protein synthesis in the liver and oviduct and in the whole body of laying hens. Poult. Sci., 69, 84-89.

Johnson R., Tomas F., Pym R.A., Fairclough R., 1986. The effect of long-term genetic selection on growth hormone secretion and protein turnover in meat-type chickens. In : Proc. 7th Europ. Poult.
Conf., M. Larbier (ed), Paris, 24-28/08/1986, 975 979.

Jones S.J., Aberle E.D., Judge M.D., 1986. Skeletal muscle protein turnover in broiler and layer chicks. J. Anim. Sci., 62, 1576-1583.

Kimball S.R., Jefferson L.S., 1988. Cellular mechanisms involved in the action of insulin on protein synthesis. Diabetes/Metab Rev., 4, 773-787.

Kino K., Okumura J., 1986a. The effect of single essential amino acid deprivation on chick growth and nitrogen and energy balances at ad libitum and equalized-food intakes. Poult. Sci., 65, 17281735 .

Kino K., Okumura J., 1986b. Improvement of body weight and nitrogen balance of chicks fed histidinefree or lysine-free diets with supplementation of graded levels of sulfur-containing amino acids. Poult. Sci., 65, 1736-1740.

Kino K., Okumura J., 1987a. Whole-body protein turnover in chicks fed control, histidine, or methionine plus cystine-free diets. Poult. Sci., 66, 13921397.

Kino K., Okumura J., 1987b. The different degradation rates of deficient amino acids in chicks fed a histidine - or methionine plus cystine-free diet. Nutr. Rep. Int., 36, 781-790.

Kita K., Okumura J., 1993. Protein synthesis in the liver and breast muscle of chicks fed on a high protein diet. Br. Poult. Sci., 34, 553-558.

Kita K., Muramatsu T., Okumura T., 1989a. Influence of excess protein intake on whole-body protein synthesis in chicks. Nutr. Rep. Int., 39, 1091-1097.

Kita K., Muramatsu T., Tasaki I., Okumura J., $1989 \mathrm{~b}$. Influence of dietary non-protein energy intake on whole-body protein turnover in chicks. Br. J. Nutr., 61, 235-244.

Kita K., Muramatsu T., Okumura J., 1993. Effect of dietary protein and energy intakes on whole-body protein turnover and its contribution to heat production in chiks. Br. J. Nutr., 69, 681-688.

Leclercq B., Chagneau A.M., Cochard T., Hamzaoui S., Larbier M., 1993. Comparative utilisation of sulphur-containing amino acids by genetically lean or fat chickens. Br. Poult. Sci., 34, 383-391.

Lobley G.E., 1993. Species comparisons of tissue protein metabolism : effects of age and hormonal action. J. Nutr., 123, 337-343.

Long C.L., Haverberg L.N., Kinney J.M., Young V.R., Munro H.N., Geiger J.W., 1975. Metabolism of 3-methylhistidine in man. Metab., 24, 929-935.

Maruyama K., Sunde M.L, Swick R.W., 1978. Growth and muscle protein turnover in the chick. Biochem. J., 176, 573-582.

McDonald M.L., Swick R.W., 1981. The effect of protein depletion and repletion on muscle-protein turnover in the chick. Biochem. J., 194, 811-819.

McNurlan M.A, Garlick P.J., 1989. Influence of nutrient intake on protein turnover. Diabetes/Metab Rev., 5, 165-189. 
McNurlan M.A., Tomkins A.M., Garlick P.J., 1979 The effect of starvation on the rate of protein synthesis in rat liver and small intestin. Biochem. J., $178,373-379$.

Meredith C.N., Wen Z.M., Bier D.M., Matthews D.E., Young V.R., 1986. Lysine kinetics at graded lysine intakes in young men. Am. J. Clin. Nutr., 43, 787-794

Muramatsu T., 1990. Nutrition and whole-body protein turnover in the chicken in relation to mammalian species. Nutr. Research Rev., 3, 211-228.

Muramatsu T., Okumura J., 1979a. Nitrogen sparing action of dietary methionine and arginine in chicks fed a protein-free diet. Nutr. Rep. Int., 19, 335-342.

Muramatsu T., Okumura J., 1979b. Effect of dietary methionine and arginine on uric acid excretion of cocks fed a protein-free diet. J. Nutr., 109, 1057 1062 .

Muramatsu T., Okumura J., 1979c. Nitrogen loss from individual tissues in chicks fed a protein-free diet with methionine plus arginine. Nutr. Rep. Int., 20, 709-716.

Muramatsu T., Okumura J., 1985. Whole-body protein turnover in chicks at early stages of growth. J. Nutr., $115,483-490$

Muramatsu T., Coates M.E., Hewitt D., Salter D.N., Garlick P.J., 1983. The influence of the gut microflora on protein synthesis in liver and jejunal mucosa in chicks. Br. J. Nutr., 49, 453-462.

Muramatsu T., Salter D.N., Coates M.E., 1985. Protein turnover of breast muscle in germ-free and conventional chicks. Br. J. Nutr., 54, 131-145.

Muramatsu T., Kato M., Tasaki I., Okumura J., 1986. Enhanced whole-body protein synthesis by methionine and arginine supplementation in protein-starved chicks. Br. J. Nutr., 55, 635-641.

Muramatsu T., Muramatsu S., Okumura J., Tasaki I., 1987a. Developmental fall in whole body protein turnover of chick embryos during incubation. $\mathrm{Br}$ Poult. Sci., 28, 165-172.

Muramatsu T., Kita K., Tasaki I., Okumura J., 1987b. Influence of dietary protein intake on wholebody protein turnover in chicks. Br. Poult. Sci., 28, 471-482.

Muramatsu T., Hiramoto K., Tasaki I., Okumura J. $1987 \mathrm{c}$. Whole body protein turnover in laying hens with special reference to protein depletion and repletion. Nutr. Rep. Int., 35, 607-614.

Muramatsu T., Hiramoto K., Tasaki I., Okumura J., 1987d. Effect of protein starvation on protein turnover in liver, oviduct and whole body of laying hens. Comp. Biochem. Physiol., 87B, 227-232.

Muramatsu T., Aoyagi Y., Okumura J., Tasaki I., 1987 e. Contribution of whole-body protein synthesis to basal metabolism in layer and broiler chickens. Br. J. Nutr., 57, 269-277.

Muramatsu T., Takai D., Kita K., Okumura J., 1990. Studies on the measurement of whole-body protein degradation in vivo in the chicken. Int. J. Biochem., $22,153-158$

Nair K.S., 1992. Protein metabolism in diabetes mellitus. Int. Symp. Burlington USA, 30/06 1/07/1991, Smith-Gordon, Nishimura.
Obled C., 1988. Aspect dynamique du métabolisme protéique au cours du développement du rat après le sevrage. Contribution à l'évaluation des méthodes de mesure des vitesses d'utilisation métabolique des acides aminés. Thèse de Doctorat d'Etat, Université de Clermont-Ferrand II.

Obled C., Barre F., Millward D.J., Arnal M., 1989 Whole body protein synthesis : studies with different amino acids in the rat. Am. J. Physiol., 257, E639-646.

Okumura J., Mori S., Muramatsu T., 1985. Relationship between food consumption and energy and nitrogen utilisation by chicks given varying amounts of standard and leucine-, isoleucine- and valine-deficient diets. Br. Poult. Sci., 26, 519-525.

Reeds P.J., Harris C.I., 1981. Protein turnover in animals : man in his context. in : Nitrogen Metabolism in Man, Waterlow J.C. and Stephen J.M.L. (eds), Applied Science publishers, London, 391-408.

Rennie M.J., Millward D.J., 1983. 3-Methylhistidine excretion and the urinary 3 -methylhistidine / creatinine ratio are poor indicators of skeletal muscle protein breakdown. Clin. Sci., 65, 217-225.

Salter D.N., Montgomery A.I., Hudson A., Quelch D.B., Elliot R.J., 1990. Lysine requirements and whole-body protein turnover in growing pigs. $\mathrm{Br}$. J. Nutr, 63, 503-513.

Saunderson C.L., Leslie S., 1983. N-Methylhistidine excretion by poultry : not all species excrete $\mathrm{N}^{\mathrm{t}}$ Methylhistidine quantitatively. Br. J. Nutr., 50, 691700 .

Saunderson C.L., Leslie S., 1988. Muscle growth and protein degradation during early development in chicks of fast and slow growing strains. Comp. Biochem. Physiol., 89A, 333-337.

Schwenk W.F., Beaufrere B., Haymond M.W., 1985. Use of reciprocal pool specific activities to model leucine metabolism in humans. Am. J. Physiol., 253, E428-434

Seve B., Reeds P.J., Fuller M.F., Cadenhead A., Hay S.M., 1986. Protein synthesis and retention in some tissues of the young pig as influenced by dietary protein intake after early-weaning. Possible connection to the energy metabolism. Reprod. Nutr. Develop., 26, 849-861.

Tesseraud S., Larbier M., Chagneau A.M., Geraert P.A., 1992. Effects of dietary lysine on muscle protein turnover in growing chickens. Reprod. Nutr. Develop., 32, 163-175.

Tesseraud S., Grizard J., Debras E., Papet I., Bonnet Y., Bayle G., Champredon C., 1993. Leucine metabolism in lactating and dry goats: effect of insulin and substrate availability. Am. J. Physiol., 265, E402-413.

Tesseraud S., Maaa N., Peresson R., Lopes J., Chagneau A.M., 1994a. Effect of age and dietary lysine deficiency on muscle protein turnover in growing chickens. In : Proc. 9th Europ. Poult. Conf., Glasgow UK, 8-12/08/1994, vol.1, 274-275.

Tesseraud S., Cammas J.C., Chagneau A.M., 1994b. Effect of age and divergent selection for body weight on muscle protein turnover in chickens. Reprod. Nutr. Develop., 34, 638-639.

Tomas F.M., Jones L.M., Pym R.A., 1988. Rates of muscle protein breakdown in chickens selected for 
increased growth rate, food consumption or efficiency of food utilisation as assessed by $\mathrm{N}^{*}$-Methylhistidine excretion. Br. Poult. Sci., 29, 359-370.

Tomas F.M., Pym R.A., Johnson R.J., 1991. Muscle protein turnover in chickens selected for increased growth rate, food consumption or efficiency of food utilisation: effects of genotype and relationship to plasma IGF-I and Growth Hormone. Br. Poult. Sci., $32,363-376$.

Waterlow J.C., 1984. Protein turnover with special reference to man. Quaterly J. Exp. Physiol. (London), 69, 409-438.
Waterlow J.C., Garlick P.J., Millward D.J., 1978. Protein turnover in mammalian tissues and the whole-body. Elsevier North Holland, Amsterdam.

Wolfe R.R., 1992. Radioactive and stable isotope tracers in biomedicine. Principles and practice of kinetic analysis. Wiley-Liss, A John Wiley et Sons, Inc publication, N.Y. Chichester, Brishane, Toronto, Singapore.

Young V.R., Munro H.R., 1978. N'-methylhistidine (3-methylhistidine) and muscle protein turnover : an overview. Fed. Proc., 37, 2291-2300.

\begin{abstract}
Protein turnover in growing chicken. Influence of dietary protein.

A possible dietary option that would ensure maximal muscle growth while avoiding excessive nitrogen loss to the environment consists of lowering the quantity of protein in the feed and using synthetic amino acids to supplement the diet. This review was undertaken in order to improve understanding of the effects of changes in the amount of protein in the diet (variations in the total quantity of protein and in its amino acid composition) on protein synthesis and breakdown. The balance between the two latter processes regulates protein deposition.
\end{abstract}

Abstract

The current methods for measuring protein synthesis have been presented here, noting the assumptions and limitations for each one. The techniques for estimating protein breakdown have also been briefly described. The turnover of whole-body and tissue proteins varies according to individual animal characteristics. For example, the fractional rate of protein synthesis decreases with age, especially for the skeletal muscles and the fractional rate of protein breakdown varies with the genotype.

The quantity of protein in the feed modifies the protein metabolism of the animal. These effects are due to the quantity of ingested protein as well as to fluctuations in the input level (protein starvation followed by protein re-feeding). The amino acid composition of the dietary protein also plays an important role. Thus a decrease in the protein intake or a deficiency in a particular amino acid may reduce the quantity of protein synthesized and, to a lesser extent, degraded. The mechanisms that regulate protein deposition in response to alterations in protein and amino acid supply, however, remain poorly understood. Further investigations of protein metabolism in different tissues and organs, including physiological and hormonal factors, need to be undertaken in order to deepen understanding of the effects of amino acid supplementation and provide a better basis for diet formulation.

TESSERAUD S., 1995. Métabolisme protéique chez le poulet en croissance. Effet des protéines alimentaires. INRA Prod. Anim., 8 (3), 197-212. 